\title{
GaN Decomposition in Ammonia
}

D.D. KOLESKE, A.E. WICKENDEN, AND R.L. HENRY

Code 6861, Electronic Science and Technology Division,

Naval Research Laboratory, Washington, D.C. 20375

\section{ABSTRACT}

GaN decomposition is studied as a function of pressure and temperature in mixed $\mathrm{NH}_{3}$ and $\mathrm{H}_{2}$ flows more characteristic of the MOVPE growth environment. As $\mathrm{NH}_{3}$ is substituted for the $6 \mathrm{SLM} \mathrm{H}_{2}$ flow, the $\mathrm{GaN}$ decomposition rate at $1000{ }^{\circ} \mathrm{C}$ is reduced from $1 \times 10^{16} \mathrm{~cm}^{-2} \mathrm{~s}^{-1}$ (i.e. 9 monolayers/s) in pure $\mathrm{H}_{2}$ to a minimum of $1 \times 10^{14} \mathrm{~cm}^{-2} \mathrm{~s}^{-1}$ at an $\mathrm{NH}_{3}$ density of $1 \times 10^{19} \mathrm{~cm}^{-3}$. Further increases of the $\mathrm{NH}_{3}$ density above $1 \times 10^{19} \mathrm{~cm}^{-3}$ result in an increase in the $\mathrm{GaN}$ decomposition rate. The measured activation energy, $\mathrm{E}_{\mathrm{A}}$, for $\mathrm{GaN}$ decomposition in mixed $\mathrm{H}_{2}$ and $\mathrm{NH}_{3}$ flows is less than the $\mathrm{E}_{\mathrm{A}}$ measured in vacuum and in $\mathrm{N}_{2}$ environments. As the growth pressure is increased under the same $\mathrm{H}_{2}$ and $\mathrm{NH}_{3}$ flow conditions, the decomposition rate increases and the growth rate decreases with the addition of trimethylgallium to the flow. The decomposition in mixed $\mathrm{NH}_{3}$ and $\mathrm{H}_{2}$ and in pure $\mathrm{H}_{2}$ flows behave similarly, suggesting that surface $\mathrm{H}$ plays a similar role in the decomposition and growth of $\mathrm{GaN}$ in $\mathrm{NH}_{3}$.

\section{INTRODUCTION}

Metallorganic vapor phase epitaxy (MOVPE) is currently being used to grow $\mathrm{GaN}$ for the fabrication of blue light emitting diodes [1], lasers [2] and for high power electronic devices [3]. For MOVPE growth, $\mathrm{NH}_{3}$ is typically used as the $\mathrm{N}$ source and high temperatures $\left(>1000{ }^{\circ} \mathrm{C}\right.$ ) are required to efficiently dissociate (i.e. $40-50 \%$ ) the $\mathrm{NH}_{3}$ [4], because of the large N-H bond strength [5]. As a result, MOVPE growth temperatures are 100-500 degrees Celsius larger than the threshold temperature for $\mathrm{GaN}$ decomposition in vacuum [6,7] and in $\mathrm{H}_{2}$ and $\mathrm{N}_{2}[8,9]$. The high rate of $\mathrm{N}_{2}$ desorption is compensated by using large flows of $\mathrm{NH}_{3}$ [10], however the extent of $\mathrm{GaN}$ decomposition that occurs during growth has not been measured.

The recent studies of Grandjean et al. [7] and Rebey et al. [11] have shown dramatic decreases in the $\mathrm{GaN}$ decomposition rate when small $\mathrm{NH}_{3}$ flows are dosed onto $\mathrm{GaN}$ surface. For example, Grandjean et al. measure a GaN decomposition rate of $5 \AA$ A $/ \mathrm{s}$ at 875 ${ }^{\circ} \mathrm{C}$ in vacuum, while under an $\mathrm{NH}_{3}$ flux of $1.7 \times 10^{17} \mathrm{~cm}^{-2} \mathrm{~s}^{-1}$, the decomposition rate drops to $0.03 \AA / s$ [7]. To explain the decrease in the $\mathrm{GaN}$ decomposition rate in $\mathrm{NH}_{3}$, a siteblocking model has been proposed where the adsorbed $\mathrm{NH}_{3}$ blocks sites necessary for $\mathrm{N}_{2}$ formation and desorption [7]. A similar site blocking mechanism has also been proposed to explain reduced $\mathrm{GaN}$ growth when the $\mathrm{NH}_{3}$ flux is increased [12]. In this paper we suggest that $\mathrm{H}$ also blocks sites on the $\mathrm{GaN}$ surface and $\mathrm{H}$ surface coverage effects must be considered in order to properly describe the GaN decomposition and growth kinetics.

\section{EXPERIMENTAL DETAILS}

Details of the GaN growth [13] and decomposition [8,9] are discussed elsewhere. The GaN films used in this study were grown and decomposed in a close-spaced showerhead MOVPE reactor. The growth and decomposition rates were determined from weight loss using an analytical balance [8]. The GaN films were grown at $1030{ }^{\circ} \mathrm{C}$ using $32 \mu$ moles of trimethylgallium (TMGa), $2 \mathrm{SLM} \mathrm{NH}_{3}$ and $4 \mathrm{SLM}$ of 


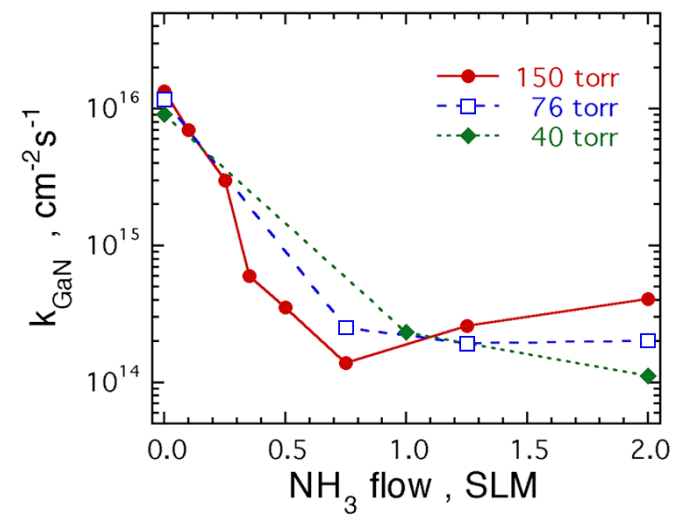

Fig 1. Plot of the GaN decomposition rate as a function of the $\mathrm{NH}_{3}$ flow rate at three different pressures. For this plot the $\mathrm{GaN}$ was heated to a temperature of $992{ }^{\circ} \mathrm{C}$ using $\mathrm{H}_{2}$ and $\mathrm{NH}_{3}$ for a total flow of 6 SLM.

$\mathrm{H}_{2}$ at pressures ranging from 40 to 300 torr. $\mathrm{GaN}$ decomposition was studied under similar flow conditions as the growth. The measured weights were converted to growth and decomposition rates per surface area (i.e. $\mathrm{cm}^{-2} \mathrm{~s}^{-1}$ ) following Ref. 10. Expressed this way, a rate of $1.14 \times 10^{15} \mathrm{~cm}^{-2} \mathrm{~s}^{-1}$ corresponds to a thickness of $1 \mu \mathrm{m}$ per hour. Temperature was calibrated by observing the melting point of 0.005 " diameter Au wire on sapphire and correlating it to a thermocouple in direct contact with the susceptor underside [8]. After 2 years of use the set point temperature needed to melt the Au wire was reproducible to within $10{ }^{\circ} \mathrm{C}$.

\section{RESULTS}

The change in the $\mathrm{GaN}$ decomposition rate, $\mathrm{k}_{\mathrm{GaN}}$, at a temperature of $992{ }^{\circ} \mathrm{C}$ as $\mathrm{NH}_{3}$ is substituted for the $\mathrm{H}_{2}$ flow is shown in Fig. 1. In Fig. 1, $\mathrm{k}_{\mathrm{GaN}}$ is plotted as the $\mathrm{NH}_{3}$ flow is increased from 0 to 2 SLM for pressures of 40, 76, and 150 torr. The total flow rate was kept constant at $6 \mathrm{SLM}$ with the balance being $\mathrm{H}_{2}$. Note that $\mathrm{k}_{\mathrm{GaN}}$ decreases from $\approx$ $1 \times 10^{16} \mathrm{~cm}^{-2} \mathrm{~s}^{-1}$ to $\approx 1 \times 10^{14} \mathrm{~cm}^{-2} \mathrm{~s}^{-1}$ as the $\mathrm{NH}_{3}$ flow increases. At 150 torr, the minimum $\mathrm{k}_{\mathrm{GaN}}$ occurs at a flow of $0.75 \mathrm{SLM}$ of $\mathrm{NH}_{3}$. At 76 torr, the $\mathrm{k}_{\mathrm{GaN}}$ minimum occurs between 1.25 and 2.0 SLM of $\mathrm{NH}_{3}$. At 40 torr no minimum in $\mathrm{k}_{\mathrm{GaN}}$ is observed. At 150 torr and a flow of $2 \mathrm{SLM}$ of $\mathrm{NH}_{3}, \mathrm{k}_{\mathrm{GaN}}$ is $\approx 4 \times 10^{14} \mathrm{~cm}^{-2} \mathrm{~s}^{-1}$.

In Fig. 2, the data from Fig. 1 are replotted as a function of the $\mathrm{NH}_{3}$ gas density, which depends on pressure. In Fig. 2, it appears that the $\mathrm{k}_{\mathrm{GaN}}$ measured at different pressures have a common minimum at a $\mathrm{NH}_{3}$ density of $\approx 1 \times 10^{19} \mathrm{~cm}^{-3}$. This $\mathrm{NH}_{3}$ density is the same order of magnitude as the calculated $\mathrm{N}$ desorption rate from $\mathrm{GaN}$, which should be $9 \times 10^{19} \mathrm{~cm}^{-2} \mathrm{~s}^{-1}$ at $992{ }^{\circ} \mathrm{C}[10]$. Two different dependencies of $\mathrm{k}_{\mathrm{GaN}}$ on the $\mathrm{NH}_{3}$ density are evident in Fig. 2. At lower $\mathrm{NH}_{3}$ density, the $\mathrm{k}_{\mathrm{GaN}}$ drops steeply as the $\mathrm{NH}_{3}$ density increases from $3 \times 10^{17} \mathrm{~cm}^{-3}$ to a value of near $1 \times 10^{19} \mathrm{~cm}^{-3}$. For $\mathrm{NH}_{3}$ densities greater than $1 \times 10^{19} \mathrm{~cm}^{-3}, \mathrm{k}_{\mathrm{GaN}}$ increases. This differs from the behavior observed by Grandjean et al., where $\mathrm{k}_{\mathrm{GaN}}$ only decreased for increasing $\mathrm{NH}_{3}$ flow [7].

To determine the dependence of $\mathrm{k}_{\mathrm{GaN}}$ on the $\mathrm{NH}_{3}$ density, $\left[\mathrm{NH}_{3}\right]$, separate fits were calculated for $\left[\mathrm{NH}_{3}\right]$ both less than and greater than $1 \times 10^{19} \mathrm{~cm}^{-3}$. For $\left[\mathrm{NH}_{3}\right]<1 \times 10^{19} \mathrm{~cm}^{-}$ ${ }^{3}$, a functional form of $\mathrm{k}_{\mathrm{GaN}}=c\left[\mathrm{NH}_{3}\right]^{x}$ was used and the data were fit by 


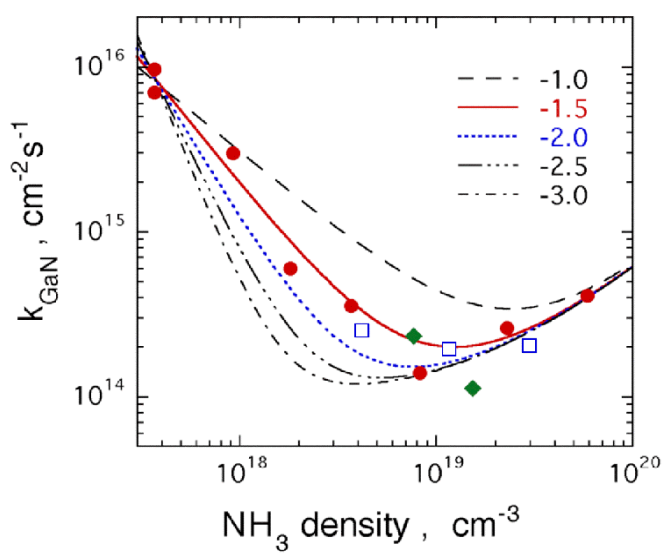

Fig. 2. Plot of the $\mathrm{GaN}$ decomposition rate measured as a function of the $\mathrm{NH}_{3}$ density at $992{ }^{\circ} \mathrm{C}$. The filled circles (red) were measured at 150 torr, the open squares (blue) were measured at 76 torr, and the filled diamonds (green) were measured at 40 torr. The lines are fits to the data using the expression $\mathrm{k}_{\mathrm{GaN}}$ $=a+b\left[\mathrm{NH}_{3}\right]+c\left[\mathrm{NH}_{3}\right]^{x}$. For the fits the values of $a$ and $b$ are the same, while the value of $x$ is fixed from -1.0 to -3.0 and $c$ is varied for the best fit.

varying $c$, keeping $x$ constant. For $\left[\mathrm{NH}_{3}\right]>1 \times 10^{19} \mathrm{~cm}^{-3}$, a linear functional form, $\mathrm{k}_{\mathrm{GaN}}=\mathrm{a}$ $+\mathrm{b}\left[\mathrm{NH}_{3}\right]$, fit the data well. The series of lines shown in Fig. 2 are a combination of the two fits (i.e. $\mathrm{k}_{\mathrm{GaN}}=a+b\left[\mathrm{NH}_{3}\right]+c\left[\mathrm{NH}_{3}\right]^{x}$ ). For the combined fits, 5 curves were calculated for 5 values of $x$ ranging from -1.0 to -3.0 , keeping the linear fit constant. Clearly, the data are best fit using with $x=-1.5$ to -2.0 .

Similar to $\mathrm{NH}_{3}$, the $\mathrm{GaN}$ decomposition rate in $\mathrm{N}_{2}$ is lower when compared to the rates measured in $\mathrm{H}_{2}$ [9], however, in mixed $\mathrm{N}_{2}$ and $\mathrm{H}_{2}$ flows the rate is substantially larger than in mixed $\mathrm{NH}_{3}$ and $\mathrm{H}_{2}$ flows. This is shown in Fig. 3, where $\mathrm{k}_{\mathrm{GaN}}$ is

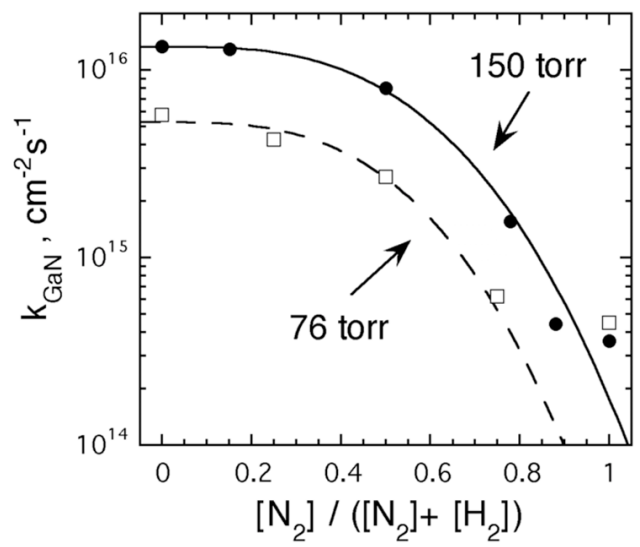

Fig. 3. Plot of the GaN decomposition rate vs. the ratio of the $\mathrm{N}_{2}$ concentration to the total (i.e. $\mathrm{N}_{2}+\mathrm{H}_{2}$ ) gas concentration. The GaN decomposition rate is shown at total pressures of 76 and 150 torr. The solid and dashed lines are cubic fits to the data. 
plotted vs. the $\mathrm{N}_{2}$ fraction of the total flow (i.e. $\left[\mathrm{N}_{2}\right]+\left[\mathrm{H}_{2}\right]$ ). For these measurements, the GaN films were annealed at $992{ }^{\circ} \mathrm{C}$ at pressures of 76 and 150 torr. In Fig. 3, $\mathrm{k}_{\mathrm{GaN}}$ at 150 torr is reduced from $1.6 \times 10^{16} \mathrm{~cm}^{-2} \mathrm{~s}^{-1}$ in pure $\mathrm{H}_{2}$ to $3.5 \times 10^{14} \mathrm{~cm}^{-2} \mathrm{~s}^{-1}$ in pure $\mathrm{N}_{2}$ (factor of 45). For a $1: 1$ mixture of $\mathrm{N}_{2}$ and $\mathrm{H}_{2}$ at 150 torr, $\mathrm{k}_{\mathrm{GaN}}$ decreases slightly to $8 \times 10^{15} \mathrm{~cm}^{-2} \mathrm{~s}^{-1}$, which is a factor of 2 compared to $\mathrm{k}_{\mathrm{GaN}}$ in pure $\mathrm{H}_{2}$. This is a significantly smaller decrease when compared to the decrease in a 1:2 mixture of $\mathrm{NH}_{3}$ and $\mathrm{H}_{2}$ (factor of 120). Note that $\mathrm{k}_{\mathrm{GaN}}$ in pure $\mathrm{N}_{2}$ and in mixed $\mathrm{H}_{2}$ and $\mathrm{NH}_{3}$ flows can be similar. For example in pure $\mathrm{N}_{2}$, $\mathrm{k}_{\mathrm{GaN}}$ is $3.5 \times 10^{14} \mathrm{~cm}^{-2} \mathrm{~s}^{-1}$, while in mixed $\mathrm{H}_{2}$ and $\mathrm{NH}_{3}$ at 150 torr, $\mathrm{k}_{\mathrm{GaN}}$ is $4 \times 10^{14} \mathrm{~cm}^{-2} \mathrm{~s}^{-1}$, as shown in Fig. 1. The solid and dashed lines in Fig. 3 are cubic fits to the $\mathrm{k}_{\mathrm{GaN}} \mathrm{vs} . \mathrm{N}_{2}$ fraction. The cubic dependence is a result of the expected dependence of surface $\mathrm{H}$ coverage (i.e. $[\mathrm{H}]^{3}$ ) for ammonia formation via the reaction $3 \mathrm{H}+\mathrm{N} \rightarrow \mathrm{NH}_{3}$. Previously, Thurmond and Logan also demonstrated $\mathrm{NH}_{3}$ formation when $\mathrm{GaN}$ is heated in $\mathrm{H}_{2}$ by titration of the basic exhaust gas [14].

In Fig. 4, the GaN decomposition and growth rates are plotted vs. pressure. In Fig. 4(a), $\mathrm{k}_{\mathrm{GaN}}$ is plotted for GaN films annealed at $992{ }^{\circ} \mathrm{C}$ in $\mathrm{H}_{2}$ [8]. Also in Fig. 4(b), the $\mathrm{GaN}$ growth rate at $1030{ }^{\circ} \mathrm{C}$ is plotted for conditions where $2 \mathrm{SLM} \mathrm{NH}_{3}, 4 \mathrm{SLM} \mathrm{H}_{2}$, and $32 \mu$ moles of TMGa were used. Finally, in Fig. 4(c) the GaN decomposition rate is plotted using the same conditions as (b) except no TMGa was used and hence decomposition was observed. Note that the decrease in the GaN growth rate as the pressure increases in Fig. 4(b) coincides with an increase in the GaN decomposition rate in Fig. 4(c). Also, the $\mathrm{k}_{\mathrm{GaN}}$ shown in Figs. 4(a) and 4(c) have a similar shape as the pressure increases and these curves are nearly identical if the $\mathrm{k}_{\mathrm{GaN}}$ in Fig 4(c) are multiplied by 30 . This similarity in shape implies that surface $\mathrm{H}$ plays a similar role in the $\mathrm{GaN}$ decomposition for both pure $\mathrm{H}_{2}$ and mixed $\mathrm{NH}_{3}$ and $\mathrm{H}_{2}$ gas environments.

\section{DISCUSSION AND CONCLUSIONS}

From the data presented in Fig. 1, the GaN decomposition rate is greater than $1 \times 10^{14}$ $\mathrm{cm}^{-2} \mathrm{~s}^{-1}$ (i.e. $\approx 1 / 10 \mu \mathrm{m} /$ hour) even in mixed $\mathrm{NH}_{3}$ and $\mathrm{H}_{2}$ flows. This is important for $\mathrm{GaN}$ growth because it suggests that some level of decomposition occurs during

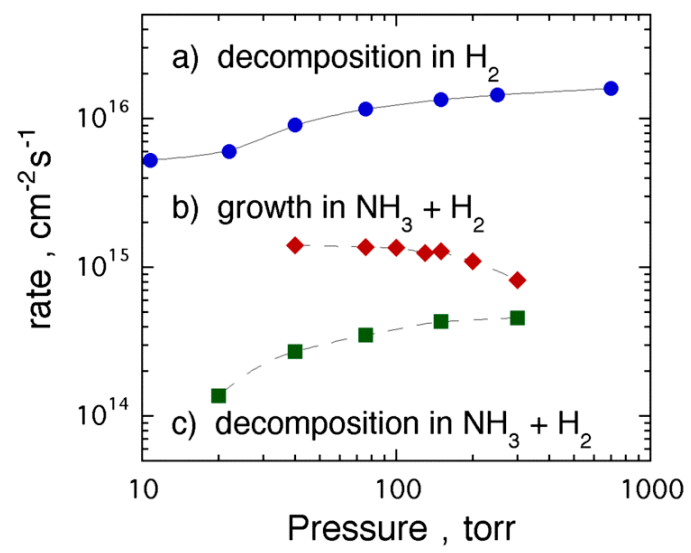

Fig. 4. Pressure dependence of the a) $\mathrm{GaN}$ decomposition rate in $6 \mathrm{SLM} \mathrm{H}_{2}$ measured at $\mathrm{T}=992{ }^{\circ} \mathrm{C}$, b) GaN growth rate using, $32 \mu \mathrm{m} \mathrm{TMGa,} \mathrm{SLM} \mathrm{NH}_{3}$ and $4 \mathrm{SLM} \mathrm{H}_{2}$ at $\mathrm{T}=1030{ }^{\circ} \mathrm{C}$, and c) $\mathrm{GaN}$ 
decomposition rate using $2 \mathrm{SLM} \mathrm{NH}_{3}$ and $4 \mathrm{SLM} \mathrm{H}_{2}$ at $\mathrm{T}=1030^{\circ} \mathrm{C}$. The only difference between b) and $\mathrm{c}$ ) is the use of TMGa in b).

growth as previously speculated [10]. Currently, we are growing GaN at a pressure of 130 torr and a temperature of $1030{ }^{\circ} \mathrm{C}$ [ 13]. Under these growth conditions, the rates for growth and decomposition are $1.2 \times 10^{15} \mathrm{~cm}^{-2} \mathrm{~s}^{-1}$ and $4 \times 10^{14} \mathrm{~cm}^{-2} \mathrm{~s}^{-1}$ respectively as shown in Fig. 4. If the growth rate equals the incorporation rate minus the decomposition rate [10], this means that the incorporation rate is $\approx 4$ times the decomposition rate under these growth conditions.

The decrease in $\mathrm{k}_{\mathrm{GaN}}$ as the $\mathrm{NH}_{3}$ density increases is due to $\mathrm{NH}_{3}$ adsorption, which blocks sites needed for GaN decomposition. As shown in Fig. 2, the decrease in $\mathrm{k}_{\mathrm{GaN}}$ depends on the -1.5 to -2.0 power of the $\mathrm{NH}_{3}$ density. Since Ga desorption from GaN has been shown to be independent of $\mathrm{H}_{2}$ pressure [8], reactions which remove $\mathrm{N}$ from the lattice probably influence the $\mathrm{GaN}$ decomposition rate more. This is clearly observed in the cubic dependence of $\mathrm{k}_{\mathrm{GaN}}$ in Fig. 3 where $\mathrm{NH}_{3}$ formation is favored at higher pressure. For $\mathrm{N}_{2}$ formation and desorption one or both of the $\mathrm{N}$ atoms diffuse across the surface until they combine to form $\mathrm{N}_{2}$. If open surface sites are necessary for $\mathrm{N}$ diffusion, blocking of these sites by $\mathrm{NH}_{3}$ or $\mathrm{H}$ would decrease the hopping rate and as a consequence the $\mathrm{N}_{2}$ formation rate would be decreased. If two (one) $\mathrm{N}$ must migrate for $\mathrm{N}_{2}$ formation, the $\mathrm{N}_{2}$ desorption kinetics would be second (first) order in the number of open surface sites. As the $\mathrm{NH}_{3}$ density on the surface increases, the decrease in the $\mathrm{GaN}$ decomposition rate should be between first and second order, i.e. $\mathrm{k}_{\mathrm{GaN}} \alpha\left[\mathrm{NH}_{3}\right]^{-1}$ or $\mathrm{k}_{\mathrm{GaN}} \alpha\left[\mathrm{NH}_{3}\right]^{-2}$, depending on the details of $\mathrm{N}_{2}$ formation and desorption. From Fig. 2, it is clear that the decrease in $\mathrm{k}_{\mathrm{GaN}}$ vs. $\mathrm{NH}_{3}$ density is closer to second order (power of -2) than first order.

At higher $\mathrm{NH}_{3}$ densities $\left(>1 \times 10^{19} \mathrm{~cm}^{-3}\right.$ ), the GaN decomposition rate increases linearly. This may be due to a decrease in the $\mathrm{NH}_{3}$ site blocking suppression of $\mathrm{N}_{2}$ desorption or a general increase in the $\mathrm{H}$ surface coverage. The increased $\mathrm{H}$ coverage could block sites necessary for $\mathrm{NH}_{3}$ adsorption. Surface $\mathrm{H}$ has also been shown to aid in $\mathrm{NH}_{3}$ adsorption and dissociation on $\mathrm{GaN}$ [15] and on $\mathrm{Al}$ [16]. In addition, large $\mathrm{H}$ coverage can favor $\mathrm{NH}_{3}$ reformation and desorption by combining with adsorbed $\mathrm{NH}_{x}$ species as suggested by Fig. 3. In contrast to $\mathrm{NH}_{3}$, site blocking with $\mathrm{H}$ should lead to an increase in the decomposition rate.

Several groups have observed decreases in growth rate when $\mathrm{H}_{2}$ is used in place of $\mathrm{N}_{2}[17,18]$, when the growth pressure is increased [19], and when higher $\mathrm{NH}_{3}$ fluxes are used for growth [20]. In Fig. 4(b), the GaN growth rate decreases as the growth pressure increases. It is clear from Fig. 4(c) that the reason the growth rate decreases is because the increased $\mathrm{GaN}$ decomposition at higher pressures. However, to fully explain the reduction in the growth rate, the full effect of gas phase depletion of the TMGa also needs to be considered.

GaN grown in $\mathrm{H}_{2}$, where $\mathrm{GaN}$ decomposition is enhanced compared to $\mathrm{N}_{2}$, appears to have better crystalline order compared to $\mathrm{GaN}$ growth in $\mathrm{N}_{2}$. Kistenmacher et al have shown that the FWHM of the GaN films grown in $\mathrm{H}_{2}$ had narrower $\mathrm{x}$-ray rocking curve linewidths and were better aligned compared (i.e. smaller mosaic dispersion) to GaN films grown in only $\mathrm{N}_{2}$ [21]. Better alignment is also observed in laterally overgrown $\mathrm{GaN}$ when $\mathrm{H}_{2}$ is used instead of $\mathrm{N}_{2}$ [22]. Schön and coworkers find smoother morphologies and better electrical properties when growth is conducted in $\mathrm{H}_{2}$ compared to $\mathrm{N}_{2}$ [23]. Better electrical properties are observed for $\mathrm{GaN}$ grown at higher pressures where $\mathrm{GaN}$ decomposition is enhanced $[13,24,25]$. Recently, we have observed a near doubling of electron mobility in films grown at 150 torr compared to 76 torr, keeping all other growth parameters the same [13]. In this study, growth at higher pressure led to increased GaN 
grain size in the films [13], suggesting that the increased GaN decomposition at higher pressure plays a significant role in determining the grain size of the $\mathrm{GaN}$ film.

\section{ACKNOWLEDGEMENTS}

We thank V.A. Shamamian, V.M. Bermudez, R.J. Gorman, M.E. Twigg, J. Freitas, M. Fatemi, and J.C. Culbertson for discussions and characterization of the films. This work is supported by the Office of Naval Research.

\section{REFERENCES}

[1] S. Nakamura, M. Senoh, N. Iwasa, S. Nagahama, T. Yamada, and T. Mukai, Jpn. J. Appl. Phys., 34, L1332 (1995).

[2] S. Nakamura, M. Senoh, S. Nagahama, N. Iwasa, T. Matushita, and T. Mukai, MRS Internet J. Nitride Semicond. Res. 4S1, G1.1 (1999).

[3] S.N. Mohammad, A.A. Salvador, and H. Morkoc, Proc. IEEE 83, 1306 (1995).

[4] S. S. Liu and D. A. Stevenson, J. Electrochem. Soc. 125, 1161 (1978).

[5] For $\mathrm{H}-\mathrm{NH}_{2}$ the bond strength is $4.8 \mathrm{eV}$. CRC Handbook of Chemistry and Physics, 66th edition, edited by R.C. Weast, (CRC Press, Cleveland, 1986).

[6] R. Groh, G. Gerey, L. Bartha, and J. I. Pankove, Phys. Status Solidi A 26, 353 (1974).

[7] N. Grandjean, J. Massies, F. Semond, S. Yu. Karpov, and R.A. Talalaev, Appl. Phys. Lett. 74, 1854 (1999).

[8] D.D. Koleske, A.E. Wickenden, R.L. Henry, M.E. Twigg, J.C. Culbertson, and R.J. Gorman, Appl. Phys. Lett. 73, 2018 (1998), erratum: ibid 75, 2018 (1999).

[9] D.D. Koleske, A.E. Wickenden, R.L. Henry, M.E. Twigg, J.C. Culbertson, and R.J. Gorman, MRS Internet J. Nitride Semicond. Res. 4S1, G3.70 (1999); http://nsr.mij.mrs.org/4S1/G3.70/

[10] For a discussion of the surface kinetics of GaN growth, see D.D. Koleske, A.E. Wickenden, R.L. Henry, W.J. DeSisto, and R.J. Gorman, J. Appl. Phys. 84, 1998 (1998).

[11] A. Rebey, T. Boufaden, B. El Jani , J. Cryst. Growth 203, 12 (1999).

[12] O. Briot, S. Clur, and R.L. Aulombard, Appl. Phys. Lett. 71, 1990 (1997).

[13] A.E. Wickenden, D.D. Koleske, R.L. Henry, R.J. Gorman, J.C. Culbertson, and M.E. Twigg, J. A. Freitas, Jr., Electron. Mat. 28, 301 (1999).

[14] C.D. Thurmond, R.A. Logan, J. Electrochem. Soc. 119, 622 (1972); R. A. Logan and C.D. Thurmond, J. Electrochem. Soc. 119, 1727 (1972)

[15] M.E. Bartram and J. R. Creighton, MRS Internet J. Nitride Semicond. Res. 4S1, G3.68 (1999).

[16] C.S. Kim, V.M. Bermudez, and J.N. Russell, Jr., Surf. Sci. 389, 162 (1997).

[17] O. Ambacher, M.S. Brandt, R. Dimitrov, T. Metzger, M. Stutzmann, R.A. Fischer, A. Miehr, A. Bergmaier, and G. Dollinger, J. Vac. Sci. Technol B 14, 3532 (1996).

[18] M. Hashimoto, H. Amano, N. Sawaki, and I. Akasaki, J. Cryst. Growth 68, 163 (1984).

[19] M.A. Khan, R.A. Skogman, R.G. Schulze, and M. Gershenzon, Appl. Phys. Lett. 43, 493 (1983).

[20] O. Briot, S. Clur, and R.L. Aulombard, Appl. Phys. Lett. 71, 1990 (1997).

[21] T. J. Kistenmacher, D.K. Wickenden, M.E. Hawley, and R.P. Leavitt, Mat. Res. Soc. Symp. Proc. 395, 261 (1996).

[22] K. Tadatomo, Y. Ohuchi, H. Okagawa, H. Itoh, H. Miyake, and K. Hiramatsu, MRS Internet J. Nitride Semicond. Res. 4S1, G3.1 (1999); http://nsr.mij.mrs.org/4S1/G3.1/

[23] O. Schön B. Schineller, M. Heuken, and R. Beccard, J. Cryst. Growth 189/190, 335 (1998).

[24] L.D. Bell, R.P. Smith, B.T. McDermott, E.R. Gertner, R. Pittman, R.L. Pierson, and G.J. Sullivan, J. Vac. Sci. Technol. B 16, 2286 (1998).

[25] T.-B. Ng, J. Han, R.M. Biefeld, and M.V. Weckwerth, J. Electronic Mat. 27, 190 (1998). 